\title{
The general plan to build an 'eco-civilization of water' city in Shandong Province on a water-system management approach
}

\author{
Pengfan $\mathrm{Xu}^{1, \mathrm{a}}$, Jinghao Wang ${ }^{1, \mathrm{~b}}$, Fang Liu, ${ }^{1, \mathrm{c},+}$, Yue Sun ${ }^{1}$, Wanxiong Song ${ }^{1}$, \\ Zhen Lu', Chonglin Fan ${ }^{1}$, Shuaizhang Han ${ }^{1}$, Chang Liu ${ }^{1}$ \\ ${ }^{1}$ School of Public Administration, Shandong Normal University, Jinan Shandong 250014, China \\ a'Bishuiyangfan2009@hotmail.com, b17864191786@139.com, 'Liufang7698@126.com
}

\begin{abstract}
Keywords: water-system management, the building of an 'eco-civilization of water' city, Shandong province

Abstract. Water source is a crucial condition for the development of a city. If the development level of a city is to be defined by water, we need to take into consideration not only the carry capacity of urban water resources under the pressure of the rapid development of social economy, but also water quality and the capacity of water environment and water ecology under the growing effect of water pollution. This paper thus gives suggestions on how to build an 'eco-civilization of water' city in Shandong province on a system management approach, analyzing concrete methods to build a water system of a city as well as an 'eco-civilization of water' city. All the cases in this paper are from previous practices of building an 'eco-civilization of water' city in Shandong Province.
\end{abstract}

\section{Introduction}

The basic characteristics of the system are holistic, order optimization, internal structure optimization, urban water management system in the concept of the building of an 'eco-civilization of water' city, requires a comprehensive thinking, to focus on the building of an 'eco-civilization of water' city as a whole, the analysis of the current water system Key elements, to explore its elements and the inherent characteristics of the basic characteristics. We must guide the cattle, to deepen the understanding of the key elements of the building of an 'eco-civilization of water' city, help to establish a modern water environment management system and its governance capacity. On the basis of this, through the site investigation of the current practice of the building of an 'eco-civilization of water' city in Shandong Province, in the view of system governance, the building of an 'eco-civilization of water' city proposed six major countermeasures and suggestions.

\section{Overview of water system management}

Urban water system. In the city's water cycle, water source, water supply, water using and water sewerage systems are interconnected to form the urban water system. The characteristic of urban water system is to achieve the goal of ensuring the benign social circulation of water: Unity of water supply and drainage, Sustainability of development, Duality of public welfare and commodity. The goal of urban water system is to ensure the benign social circulation of water and realize the sustainable utilization of water resources. ${ }^{(1)}$

The difference between water system governance and traditional governance. System governance is the integration of various factors, combining the water and the governance of Mountain, forest, treatment of farmland organically, to solve the problem of aquatic resources. Systematicness sees a city as a unified life organism, paying attention to the conformity of various system elements, and avoiding the thought of dividing and conquering. Water resources management is directed not only at the natural aspects of governance, but also the social governance. We need to adhere to the overall planning, scientific guidance of water resources protection and development. And we need to take into consideration, considering the natural, economical and social factors comprehensively,

\footnotetext{
+ Corresponding author.E-mail address: liufang7698@126.com.

${ }^{(1)}$ Ministry of water resources. Small and medium-sized rivers project preliminary design guidance [R]. 2010.
} 
considering the basin and regional characteristics, scientifically determining the planning and Construction Unit. ${ }^{1}$

System governance needs to exert multiple force, integrating the government-society and other multi-party participation. The biggest difference between the two is that there are many subjects involved in system governance, and the mechanism of governance is much more complicated than traditional management. The relationship between the parties involved in system governance, in addition to the hierarchical control of this longitudinal relationship,involves also many lateral aspects. Government and market cooperate in system governance. ${ }^{(2)}$ In other word,government not only to make the market play a good role in the water resources allocation,market but also to exert the government's overall planning, policy guidance and system safeguard in the protection of water safety. ${ }^{3}$

\section{Water system of governance under the perspective of ecological civilization construction}

The significance of water system of governance perspective to promote urban water ecological civilization construction. Now water resources projects in China is undergoing a transformation from the key stage of the traditional water conservancy to modern water conservancy. President Xi proposes a scientific method of water affair management, and shows a bright way for strengthening the governance of water、 ensuring the safety of the water、solving the problem of water, Among them, a way to the system of governance should be the fundamental way to solve the problem of complex water. Only by insisting on system management implement System of water conservancy by science, can we combine with the new urbanization development. As a whole of elements,Build community life to solve the problems of under the new normal complex water. ${ }^{(4)}$

Water ecological civilization construction from the perspective of water system governance. We have put forward the five perspectives, the perspective of water using includes: the use of water, the water ecological environment, the management of the water, the safety of the water, the culture of the water.

\section{The water system under the view of governance, promoting measures featured water city construction of ecological civilization in Shandong province}

Combing ecological civilization construction of Shandong province water feature, we propose"Mountain - City - River - Lake -Field - Humanity"The construction of six large plates and 24 courses of action. ${ }^{5}$

"Conservation - Insurance - Treatment - Prevention" - Sponges and urban construction in small watershed. The definition of "sponge city", which is the result of natural, is based on resource carrying capacity of the environment to build a scientific and reasonable layout of urbanization, to minimize interference and damage to natural, natural accumulation, infiltration, natural purification. Let the city like a sponge, when rain water, drought on water absorption and then "spit" out.

"Sponge homes" and "sponge city", is building "landscape forest field Lake", life community of organic part. To according to" system governance "method, integrated consider city precipitation, and

\footnotetext{
${ }^{(1)}$ Ministry of water resources. The Ministry of water resources held the group's leading group to study and implement the important speech spirit of president Xi Jinping on water safety [R]. 2014.

(2) Ochowiak,Marek \& Matuszak,Magdalena, et al. The modified swirl sedimentation tanks for water purification [J]. Journal of environmental management, 189(10), 2017: 22-28.

${ }^{(3)}$ Fernandes,J.P \& Freire,M, et al. Using modeling tools for implementing feasible land use and nature conservation governance systems in small islands The Pico Island (Azores) case-study [J]. Journal of environmental management. 189(10), 2017: 1-13.

(4) Smith,Laurence \& Inman,Alex, et al. Mitigation of diffuse water pollution from agriculture in England and China, and the scope for policy transfer [J]. Land use policy, 61(4), 2017: 208-219.

${ }^{5}$ Liu Fang, Miao Wang. Study on the system model construction of water ecological civilization construction [J]. China Population Resources and Environment, 2016, 26(05): 117-122.
} 
Xia pad surface, and drain Canal, and water resources using, factors, take" storage, and delay, and infiltration, and net, and with, and row ", variety combination measures, perfect city green and municipal drainage flood, system programme, common formed" landscape forest field Lake "life community. ${ }^{1}$

"Scenery - Save - Back - Match" - Promoting the construction of landscape city. Mountain: First is the mountain water regulating articles; second is focusing on small watersheds in mountainous area; third is conditionally to create national parks. Water: one is to protect the river aquatic space; the other is urban and rural low storage space reserved.

Water: Scientifically water control, building community, and adhere to the people-centred, adhere to the people-oriented, scientific water management concept of harmony between human and water and change people and water for land, human and ecological competition for water, the phenomenon of water to human suffering. From "against a scourge" into "management of flood resources" integrated play "Mountain Lake" its detention storage, make the flood victims for the treasure, being used. ${ }^{2}$

"Useage - Clearance - Gallery - Adjust" - Construction of multifunctional water network. The "spatial equilibrium "should be adopted to solve the problem of water resource allocation; the "system of governance "should be adopted to solve the problem of the complex problem of water security to insist "punches with both hands", short of solving water management problems, while also insisting on "pollution", and solve the water ecological degradation.

Water source can benefit not only to swim in the River, flood and drainage, to maintain the ecological functions, but also to enhance the landscape, to increase function of interesting people, multifunctional network construction so the main river and its tributaries to achieve "smooth water of the river" plays an important role.

"Repair - Expand - Protect - Foster" - Good Lake and reservoir construction. To resolutely curb encroachment reduced trend in natural lakes, strict protection and care for the Lakes. On the one hand, to according to China water, and flood control method provides, ban surrounding Lake made to, has reclamation of, should according to national provides of flood control standard has plans to back to also Lake, also to further strengthening Lake dredging work, prevent deposition lost function; On the other hand, to with national and the local Government on water of increasingly attention and input of increased, efforts built artificial lake, make up natural lake of reduced, improve regional water rate. Such as the construction of the reservoir of a mountain area-Lake, creating Plains landscape-Lakes, build a wetland Lake, and so on. ${ }^{(3)}$

"Save - Control - Rule - Set"- Promoting the construction of ecological irrigation district. Firstly, we should adhere to the water, water conservation, water control; Secondly, we should restructure, integrate, centralize control. In the auxiliary project and water saving reform to establishing and implementing the scientific concept of development, increase the intensity of soil erosion prevention, promoting the construction of ecological civilization, created man in harmony with nature, water drains blocked bank beautiful eco-irrigation district.

"Make - Build - Transfer - UE" - Build a landscape of Qi Lu culture. Shandong province has a long history, for the water city construction of ecological civilization left a valuable legacy. Age, already have a 2600 years of history of the Spa culture, modern historical and cultural heritage and should be red and culture form a logical one, bringing out the protection plan. Traditional water city construction of ecological civilization and the Qi Lu culture should be combined to heritage and carry forward the splendid Qi Lu culture and build a modern landscape of Qi Lu culture.

\footnotetext{
${ }^{(1)}$ Fang Zijie, Ke Shengshao. Using "systematic approach" to address complicated water problems under new normal state [J], China Water Resources, 2015(6): 8-10.

${ }^{2}$ Chai Junfeng. On the measures and suggestions in the governance of Zhang River system [J]. Water conservancy and hydropower construction, 2016(4): 148-151.

${ }^{3}$ Broman, Goran \& Robert, Karl-Henrik, et al. Science in support of systematic leadership towards sustainability[J]. Journal of cleaner production, 140(1), 2017: 1-9.
} 


\section{Conclusions}

In the system of governance perspective, the whole of civilized and ecological city construction starting from the water, through factor analysis of urban water systems, help Increase awareness of the basic features of each of these elements, straighten out the order, the internal relations between the various elements and interactions, clearly understanding the internal structure of urban water system. On this basis, starting from the whole thing, focus on key elements of the internal structure optimization of urban water system and associated with a typical case. Through this " theory and experience " type of pattern can help always adhere to the "System Management " thinking and directions, meanwhile puts forward countermeasures and suggestions for policy making or has laid a solid foundation.

\section{Acknowledgements}

This paper is the research result of Shandong provincial level water conservation scientific research and technology promotion project "water resources balances sheet and its application research in public project governance" (SDSLKY201604). It is the key project of Shandong Province Soft Science Research Project (2016RZB01005), at the same time, the research is based on the research project of the Humanities and Social Sciences Research Program of Shandong Province (J16YF13) Research on the multi-dimensional decision-making innovation of poverty alleviation project management from the perspective of dynamic social network.

\section{References}

[1] Ochowiak, Marek \& Matuszak, Magdalena, et al. The modified swirl sedimentation tanks for water purification [J]. Journal of environmental management. 189 (10), 2017: 22-28.

[2] Smith, Laurence \& Inman, Alex, et al. Mitigation of diffuse water pollution from agriculture in England and China, and the scope for policy transfer [J]. Land use policy. 61 (4), 2017: 208-219.

[3] Broman, Goran \& Robert, Karl-Henrik, et al. Science in support of systematic leadership towards sustainability [J]. Journal of cleaner production. 140 (1). 2017:1-9.

[4] Fernandes, J.P \& Freire, et al. Using modeling tools for implementing feasible land use and nature conservation governance systems in small islands The Pico Island (Azores) case-study[J]. Journal of environmental management. 189(10), 2017: 1-13.

[5] Liu Fang, Miao Wang. Study on the system model construction of water ecological civilization construction[J]. China Population Resources and Environment, 2016, 26(05): 117-122.

[6] Fang Zijie, Ke Shengshao. Using "systematic approach" to address complicated water problems under new normal state [J]. China Water Resources, 2015(6): 8-10.

[7] Chai Junfeng. On the measures and suggestions in the governance of Zhang River system [J]. Water conservancy and hydropower construction, 2016(4): 148-151.

[8] Ministry of water resources. Small and medium-sized rivers project preliminary design guidance [R]. 2010.

[9] Ministry of water resources. The Ministry of water resources held the group's leading group to study and implement the important speech spirit of president Xi Jinping on water safety [R]. 2014. 